Research Article

\title{
Healthy Aging and Compensation of Sentence Comprehension Auditory Deficits
}

\author{
Marcela Lima Silagi, Camila Maia Rabelo, Eliane Schochat, and Letícia Lessa Mansur
}

Department of Physical Therapy, Speech-Language Pathology and Occupational Therapy, School of Medicine, University of São Paulo, 05360-000 São Paulo, SP, Brazil

Correspondence should be addressed to Marcela Lima Silagi; marcela_silagi@hotmail.com

Received 16 April 2015; Accepted 30 September 2015

Academic Editor: Emmanuel Moyse

Copyright ( 2015 Marcela Lima Silagi et al. This is an open access article distributed under the Creative Commons Attribution License, which permits unrestricted use, distribution, and reproduction in any medium, provided the original work is properly cited.

\begin{abstract}
Objectives. To analyze the effect of aging on sentence auditory comprehension and to study the relationship between this language skill and cognitive functions (attention, working memory, and executive functions). Methods. A total of 90 healthy subjects were divided into three groups: adults (50-59 years), young-old (60-69 years), and old-old (70-80 years). Subjects were assessed using the Revised Token Test. The measures used for performance analysis were number of correct answers (accuracy) and execution time of commands on the different subtests. Results. Regarding accuracy, groups showed similar performance on the first blocks, but the young-old and old-old performed worse than adults on blocks 9 and 10. With respect to execution time, groups differed from block 2 (i.e., the groups differed for all blocks, except for block 1), with the worst performance observed in the old-old group, followed by that of the young-old group. Therefore, the elderly required more time to attain performance similar to that of adults, showing that time measurements are more sensitive for detecting the effects of age. Sentence comprehension ability is correlated with cognitive test performance, especially for global cognition and working memory tests. Conclusions. Healthy aging is characterized by the ability to compensate for difficulties in linguistic processing, which allows the elderly to maintain functional communication.
\end{abstract}

\section{Introduction}

It is generally agreed that aging causes language disorders in the elderly, but this issue has not received sufficient research attention. With advancing age, disparities in cognitive performance and language among individuals increase. Studies have shown that the aging process causes heterogeneous changes in language and have sought to explain the reasons for the decline observed in certain functions and the sparing of others $[1,2]$.

There is extensive literature about changes in oral production with aging. It is known that vocabulary begins to decline starting at 50 years of age, whereas phonetic-phonological skills remain largely intact until very old age $[3,4]$. Regarding language comprehension, a smaller number of investigations seeking to establish the effects on auditory processing deficits are observed. Auditory comprehension of sentences, especially of complex phrases, is an aging-related complaint [5], but the underlying causes of this decline and why some elderly subjects do not develop this deficit remains unclear.
Hearing deficits, both central and peripheral, are important factors to consider in language comprehension in the elderly [6, 7]. Moreover, the neural network of language comprehension processing is intrinsically related to other cognitive functions networks, such as working memory, attention, and executive function [8-10].

One of the mechanisms that could explain cognitivelinguistic heterogeneity manifested in normal elderly is cognitive reserve [11]. Brain networks are associated with cognitive reserve in adults, and compensation mechanisms can be observed in older elderly [12], as a result of the plasticity of the central nervous system [13].

Studies involving neuroimaging show inter- [14] and intrahemispheric reorganizations [15] associated with compensation during the aging process. Compensation becomes evident when images are correlated with stability or superiority of cognitive performance on several tasks, including language tasks [16]. 
One of the most widely used tests for assessing auditory sentence comprehension is the Token Test (TT) [17], which was devised to evaluate auditory memory and syntactic comprehension. The TT explores the ability to retain a significant number of items grouped into sections.

The TT has been the subject of several studies and is available in short versions [18-20], which have proven to be as effective as long versions for the detection of pathological conditions such as aphasia $[18,21-23]$ and neurodegenerative diseases [24-26].

Studies on the effects of sociodemographic variables in subjects without brain injury show a strong educational effect on performance in the TT, but the effect of aging is controversial, depending on the version of the test employed, the scoring system used, and the age range studied, with decline being most evident beyond 65 years of age [21, 27-30].

The study by Kim et al. [31] is notable for having used a response time measurement (measured from the end of the command until the initial touch of the piece, at natural speed) to verify the correlations between age and test performance, stating that these time measurements can be more sensitive for detecting the effects of aging.

Against this background, the main objective of this study was to compare the performance of adult, young-old, and oldold subjects in auditory sentence comprehension using the Revised Token Test (RTT) [22]. To study the effect of aging on this linguistic task, we used the number of correct answers (accuracy) and execution time of commands in the different subtests of the test.

An additional aim was to study the correlation of sentence comprehension ability with cognitive functions. The cognitive tests used for correlation with RTT were the MiniMental State Examination (MMSE) [32, 33] (global cognitive screening), semantic verbal fluency (FVS) [34] (semantic memory and executive functions), direct digit span [35] (attention and information storage capacity), and reverse digit span [35] (working memory and mind control for the operationalization of information).

The present study made differential use of the time measure and the execution time measure, because it is assumed to be more sensitive for detecting performance differences between age groups and allows researchers to observe the use of cognitive strategies for the implementation of full commands (manipulation of the tokens) and not only the timing between the giving of the command and the initial touch, for measuring the reaction time and response time. To the best of our knowledge, no studies using this form of time measurement for evaluating performance on the TT are available.

This study began with the hypothesis that auditory comprehension is a vulnerable skill in aging, but a subgroup of the healthy population retains performance similar to that of younger people. Elderly who maintain high performance do so through compensation mechanisms, which are related to the recruitment of cognitive functions that sustain language (e.g., attention, executive function, and working memory).

\section{Materials and Methods}

2.1. Ethics. This study is part of the larger project "Aging Maintaining Functions: elderly in the 2020s" run by the Department of Physical Therapy, Speech Therapy and Occupational Therapy, School of Medicine, University of São Paulo, Brazil. The study was supported by the National Council of Scientific and Technological Development (CNPq; process number 557887/2009-7) and was approved by the Research Ethics Committee of the University Hospital of the Medical School, University of São Paulo (registration CEP-HU/USP: 1005/10; SISNEP CAAE: 0034.0.198.000-10). After receiving complete information about the procedures, participants signed the consent form.

2.2. Participants. The study sample comprised 90 healthy subjects of both genders, aged 50 to 80 years, with over 5 years of formal education who were native Brazilian Portuguese speakers without cognitive complaints, with functional hearing and vision, with no motor deficits. Participants were equally divided into three groups according to age: Group 1, adults (50-59 years); Group 2, young-old (60-69 years); and Group 3, old-old (70-80 years).

2.2.1. Inclusion Criteria. To be eligible for study enrollment, participants had to meet the inclusion criteria for studies in neuropsychology described in the Mayo Older American Normative Studies (MOANS) [36]. These criteria primarily include an absence of cognitive complaints or psychiatric/neurologic disorders, no recent use of psychoactive drugs, and no alcohol dependence.

The subjects were submitted to cognitive tests and asked about communication functionality in everyday life. Inclusion in the study was conditional on obtaining scores consistent with normative values for the Brazilian population on the following tests:

(i) Mini-Mental State Examination (MMSE) [32, 33]: it is used for cognitive screening, with a minimum score of 25 points for individuals with 1-4 years of education, 26 points for $5-8$ years, 28 points for over 8 years, and 29 points for over 11 years of education.

(ii) Adapted Cognitive Change Questionnaire (QMC) [37]: it includes questions about changes in performance of complex activities of daily living. The adopted cut-off score was 2 points.

(iii) Geriatric Depression Scale-15 [38, 39]: it is used to detect depressive symptoms that could impact cognitive performance. The adopted cut-off score was 5 points.

(iv) Functional Assessment of Communication Skills for Adults (ASHA-FACS) [40, 41]: the social communications domain was used for scoring. The test consists of 21 questions on the implementation of tasks independently, with different levels of assistance (minimum, minimum-moderate, moderate-maximum, and maximum) or impossibility of fulfillment. The final score is obtained by calculating the arithmetic mean of the scores attained on each question, with a maximum of 7 points.

All groups performed audiometric exams, with hearing thresholds of up to $40 \mathrm{~dB}$ horizontal line (HL) (at 500, 
1000 , and $2000 \mathrm{~Hz}$ ), a symmetrical hearing configuration, and the presence of a $\mathrm{V}$ wave evoked with a click stimulus in the auditory brainstem response (ABR) (difference of up to $0.2 \mathrm{~ms}$ between the ears).

The subjects also underwent evaluations with an ophthalmologist and physiotherapist for exclusion of visual and motor abnormalities that may have compromised the tests run.

2.2.2. Exclusion Criteria. Subjects with scores below the cutoff score on cognitive tests, depressive symptoms, and other psychiatric or neurological disorders were excluded. Subjects who failed the auditory, visual, and motor tests were also removed from the sample.

\subsection{Procedures}

2.3.1. Revised Token Test (RTT). To compare the performance of adults, young-old, and old-old subjects auditory sentence comprehension, we used the Brazilian Portuguese version of the RTT. The test consists of 50 commands grouped into ten sections. The task entailed manipulating tokens of different shapes, sizes, and colors: 20 tokens of five different colors (blue, red, green, white, and black), two formats (squares and circles), and two sizes (small and large).

Semantic content and cultural factors are minimized because the requested information is reduced to the size, shape, and color of the tokens.

However, there are a progressive number of requests, and extent of information, in order to recruit working memory. Subtests 1 to 4 have simple and composite imperative statements that assess understanding of color, size, and shape. Subtests 5 to 8 require comprehension of prepositions related to visual-spatial content in the handling of one part (active part) over another (inactive part). In the last two subtests $(9,10)$, there is an increase in both information and linguistic complexity by introducing prepositional phrases, adverbial clauses, and compound sentences combined in heterogeneous commands on many dimensions, as shown in Table 1. Adequate performance of commands requires the cognitive support of attention, working memory, executive function skills, and language processing at different levels [22].

The test was applied individually in a quiet environment, as recommended in the original manual. Pretest instructions were given to familiarize the subjects with the concepts of color, shape, and size. All commands were given aloud by a speech therapist experienced in language assessment who was a native speaker of Brazilian Portuguese.

The commands were given at a normal speech rate for Brazilians living in São Paulo [42] and at an intensity of $60-70 \mathrm{~dB}$ sound pressure level (SPL) or approximately $50 \mathrm{~dB}$ hearing level (HL). Regarding prosody, the presentation of each unit in each command had no special inflection or pauses between units; that is, the prosodic features (speed, fluency, emphasis, intonation, and articulation) were constant across commands.

2.3.2. Cognitive Evaluation. To study the relationship between cognitive functions and sentence comprehension ability,
TABLE 1: Examples of the complexity of RTT commands in each block.

\begin{tabular}{ll}
\hline Block & Examples \\
\hline 1 & Touch the black circle \\
2 & Touch the big green circle \\
3 & Touch the green square and the black square \\
4 & Touch the big green square and the little black square \\
5 & Put the black circle above the white square \\
6 & Put the big red square in front of the big white circle \\
7 & Put the black circle to the left of the white square \\
8 & Put the little green circle to the left of the big red square \\
9 & Instead of the green square, touch the black square \\
10 & $\begin{array}{l}\text { Touch the big black square unless you have touched the } \\
\text { little red circle }\end{array}$ \\
\hline
\end{tabular}

the score and the total execution time in the RTT were correlated with the following tests:

(i) Mini-Mental State Examination (MMSE) [32, 33]: it is used for cognitive screening. The examination presents temporal and spatial orientation, immediate memory, attention and calculation, delayed recall, language (reading, writing, naming, and repetition) subtests, and design copy for assessing visuospatial skills.

(ii) Semantic verbal fluency (FVS), animal category [34]: it evaluates semantic memory and executive functions. Subjects were instructed to list as many animals as they could in one minute.

(iii) Digit span in direct and reverse order [35]: the subjects should repeat increasing sequences of numbers in direct and reverse order. The direct sequence evaluates attention and information storage capacity, whereas the reverse sequence assesses working memory and mind control for the operationalization of information.

2.4. Data Analysis. Performance on the RTT was analyzed with respect to number of correct answers (accuracy) and execution time of commands. For number of correct answers, one point was awarded for each correct answer. The analysis considered the sum of correct answers under the total score and on each subtest. The analysis of execution time (time difference between end of command and full completion of action: touching or manipulating the pieces) was timed and measured in seconds. The analysis considered the sum of the times taken on each block and the total time.

For descriptive analysis, means and standard deviations of all demographic variables and performance on cognitive tests and on the RTT for the three age groups were calculated. Comparison of means for continuous data was performed using one-way ANOVA, given the Gaussian distribution of the data. When the difference between groups was statistically significant, a post hoc (Bonferroni) test was applied for pairwise comparison. 
TABLE 2: Demographic and cognitive characteristics of the sample.

\begin{tabular}{|c|c|c|c|c|c|}
\hline Variable & $\begin{array}{c}\text { Group } 1 \\
\text { mean }(S D)\end{array}$ & $\begin{array}{c}\text { Group } 2 \\
\text { mean (SD) }\end{array}$ & $\begin{array}{c}\text { Group } 3 \\
\text { mean }(\mathrm{SD})\end{array}$ & $p$ value & Multiple comparisons $(<0.05)$ \\
\hline Age & $54.3(3.3)$ & $64.3(3.1)$ & $74.3(5.4)$ & $<0.001^{*}$ & $\mathrm{G} 1 \times \mathrm{G} 2 \times \mathrm{G} 3$ \\
\hline Education & $10.9(3.5)$ & $10.8(3.5)$ & $10.8(3.8)$ & 0.991 & ns \\
\hline \multicolumn{6}{|l|}{ Gender } \\
\hline M & 5 & 10 & 7 & \multirow{2}{*}{0.530} & \multirow{2}{*}{ ns } \\
\hline $\mathrm{F}$ & 19 & 14 & 17 & & \\
\hline MMSE & $28(1.1)$ & $27.5(1.8)$ & $27.7(1.7)$ & 0.511 & ns \\
\hline CCQ & $0.2(0.5)$ & $0.1(0.3)$ & $0.4(1.0)$ & 0.584 & ns \\
\hline GDS & $1.8(1.4)$ & $1.3(1.2)$ & $1.2(1.0)$ & 0.214 & ns \\
\hline SVF & $17.4(5.2)$ & $16.6(4.7)$ & $17.7(3.8)$ & 0.691 & ns \\
\hline DS-DO & $5.6(1.3)$ & $5.6(0.9)$ & $5.8(0.9)$ & 0.670 & ns \\
\hline DS-RO & $3.5(1.1)$ & $3.5(0.9)$ & $4.0(1.4)$ & 0.603 & ns \\
\hline ASHA-FACS & $6.9(0.0)$ & $6.9(0.0)$ & $6.9(0.0)$ & 0.252 & ns \\
\hline
\end{tabular}

$\mathrm{SD}=$ standard deviation; $\mathrm{F}$ = female; $\mathrm{M}=$ male; $\mathrm{MMSE}=$ Mini-Mental State Examination; $\mathrm{CCQ}=$ Cognitive Change Questionnaire; GDS = Geriatric Depression Scale; SVF = semantic verbal fluency; DS-DO = digit span in direct order; DS-RO = digit span in reverse order; ASHA-FACS = Functional Assessment of Communication Skills for Adults.

${ }^{*}$ Statistically significant difference.

TABLE 3: Performance of groups on the RTT as measured by number of correct answers (accuracy).

\begin{tabular}{|c|c|c|c|c|c|}
\hline Subtest & $\begin{array}{c}\text { Group } 1 \\
\text { mean (SD) }\end{array}$ & $\begin{array}{c}\text { Group } 2 \\
\text { mean (SD) }\end{array}$ & $\begin{array}{c}\text { Group } 3 \\
\text { mean (SD) }\end{array}$ & $p$ value & $\begin{array}{c}\text { Multiple comparisons } \\
(<0.05)\end{array}$ \\
\hline 1 & $5.0(0.0)$ & $4.8(0.6)$ & $5.0(0.0)$ & 0.199 & ns \\
\hline 2 & $4.9(0.2)$ & $4.7(0.7)$ & $4.8(0.5)$ & 0.596 & ns \\
\hline 3 & $4.7(0.6)$ & $4.8(0.3)$ & $5.0(0.0)$ & 0.051 & ns \\
\hline 4 & $4.6(0.9)$ & $4.7(0.5)$ & $4.6(0.5)$ & 0.778 & ns \\
\hline 5 & $4.4(0.9)$ & $4.2(1.1)$ & $4.2(1.0)$ & 0.726 & ns \\
\hline 6 & $4.0(1.1)$ & $3.9(1.4)$ & $3.8(1.0)$ & 0.843 & ns \\
\hline 7 & $4.5(0.7)$ & $4.2(1.1)$ & $4.5(0.6)$ & 0.520 & ns \\
\hline 8 & $4.2(1.3)$ & $4.1(1.0)$ & $4.1(1.1)$ & 0.972 & ns \\
\hline 9 & $4.2(0.5)$ & $3.6(0.7)$ & $3.3(0.8)$ & $<0.001^{*}$ & $\begin{array}{l}\mathrm{G} 1 \times \mathrm{G} 2 \\
\mathrm{G} 1 \times \mathrm{G} 3\end{array}$ \\
\hline 10 & $3.8(1.0)$ & $3.1(1.3)$ & $2.8(1.4)$ & $0.024^{*}$ & $\begin{array}{l}\mathrm{G} 1 \times \mathrm{G} 2 \\
\mathrm{G} 1 \times \mathrm{G} 3\end{array}$ \\
\hline Total & $44.5(5.0)$ & $42.6(5.4)$ & $42.4(4.8)$ & 0.319 & $\mathrm{~ns}$ \\
\hline
\end{tabular}

$\mathrm{SD}=$ standard deviation.

${ }^{*}$ Statistically significant difference.

The distribution of subgroups according to gender was compared by Pearson's chi-square test. Pearson's coefficient was calculated to determine the association between performance on the RTT and cognitive performance. The same test was also used to verify the correlation between number of correct answers and execution time on the RTT.

A 5\% level of statistical significance was adopted for all analyses. Analyses were performed using the statistical software program BIOESTAT 5.0 [43].

\section{Results}

3.1. Demographic, Cognitive, and Communicative Functionality Characteristics. The demographic characteristics of the sample and performance on the cognitive tests are presented in Table 2. All groups differed with respect to age, but there was no statistically significant difference for the other variables, including education, which shows that the groups were well matched and homogeneous, allowing for the observation of aging effects.

\subsection{Age Effect on RTT: Number of Correct Answers (Accuracy)} and Execution Time. The performance of the groups, as measured by the number of correct answers on each subtest and total RTT, is presented in Table 3. All groups showed similar performance on most subtests (1 to 8), but adults differed from young and old-old on the last two subtests (9 and 10).

Table 4 shows the performance of the groups regarding execution time for each subtest and for the total test. The groups showed similar performance on subtest 1 . The oldold group required a significantly longer time to perform 
TABLE 4: Performance of groups on the RTT as measured by execution time.

\begin{tabular}{|c|c|c|c|c|c|}
\hline Subtest & $\begin{array}{c}\text { Group 1 } \\
\text { mean (SD) }\end{array}$ & $\begin{array}{c}\text { Group } 2 \\
\text { mean }(\mathrm{SD})\end{array}$ & $\begin{array}{c}\text { Group } 3 \\
\text { mean (SD) }\end{array}$ & $p$ value & $\begin{array}{c}\text { Multiple comparisons } \\
(<0.05)\end{array}$ \\
\hline 1 & $3.7(2.1)$ & $6.4(4.2)$ & $7.5(4.6)$ & 0.057 & ns \\
\hline 2 & $5.1(2.2)$ & $7.0(3.3)$ & $9.2(6.1)$ & $0.006^{*}$ & $\begin{array}{l}\mathrm{G} 1 \times \mathrm{G} 3 \\
\mathrm{G} 2 \times \mathrm{G} 3\end{array}$ \\
\hline 3 & $6.4(3.5)$ & $9.4(7.5)$ & $11.2(7.9)$ & $0.047^{*}$ & $\mathrm{G} 1 \times \mathrm{G} 3$ \\
\hline 4 & $9.7(4.9)$ & $11.7(8.1)$ & $14.1(6.6)$ & $0.048^{*}$ & $\mathrm{G} 1 \times \mathrm{G} 3$ \\
\hline 5 & $23.1(7.7)$ & $28.5(10.6)$ & 31.3 (11.1) & $0.017^{*}$ & $\begin{array}{l}\mathrm{G} 1 \times \mathrm{G} 2 \\
\mathrm{G} 1 \times \mathrm{G} 3\end{array}$ \\
\hline 6 & $26.2(7.0)$ & $30.8(10.2)$ & 37.5 (13.9) & $0.002^{*}$ & $\begin{array}{l}\mathrm{G} 1 \times \mathrm{G} 3 \\
\mathrm{G} 2 \times \mathrm{G} 3\end{array}$ \\
\hline 7 & $20.3(7.0)$ & $24.0(10.3)$ & $26.9(8.0)$ & $0.034^{*}$ & $\mathrm{G} 1 \times \mathrm{G} 3$ \\
\hline 8 & $18.4(8.0)$ & $33.4(11.5)$ & 33.7 (9.7) & $0.018^{*}$ & $\begin{array}{l}\mathrm{G} 1 \times \mathrm{G} 2 \\
\mathrm{G} 1 \times \mathrm{G} 3\end{array}$ \\
\hline 9 & $15.6(8.5)$ & $22.1(10.0)$ & $24.7(9.2)$ & $0.003^{*}$ & $\begin{array}{l}\mathrm{G} 1 \times \mathrm{G} 2 \\
\mathrm{G} 1 \times \mathrm{G} 3\end{array}$ \\
\hline 10 & $18.8(10.1)$ & $23.2(8.5)$ & $25.4(8.4)$ & $0.047^{*}$ & $\mathrm{G} 1 \times \mathrm{G} 3$ \\
\hline Total & $148.7(37.4)$ & $190.1(52.1)$ & $211.9(55.4)$ & $0.002^{*}$ & $\begin{array}{l}\mathrm{G} 1 \times \mathrm{G} 2 \\
\mathrm{G} 1 \times \mathrm{G} 3\end{array}$ \\
\hline
\end{tabular}

$\mathrm{SD}=$ standard deviation

${ }^{*}$ Statistically significant difference.

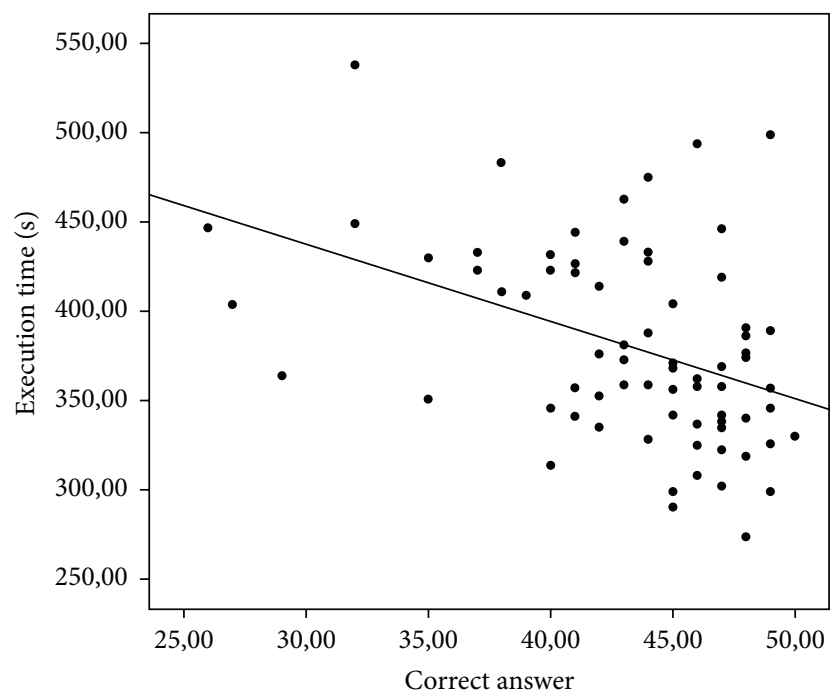

FIGURE 1: Correlation between number of correct answers (accuracy) and execution time on each RTT subtests.

the RTT test than did the young-old and adult groups. The old-old subjects differed from adults on all subtests (except for subtest 1 ) and from the young-old on subtests 2 and 6 . The young-old group showed a longer execution time than adults on subtests 5,8 , and 9 and a longer total time.

Although the number of correct answers did not differentiate the groups with respect to total score, Pearson's correlation coefficient revealed that the variable number of correct answers had a statistically significant negative correlation with execution time ( $p<0.001)$; that is, the longer the execution time, the lower the number of correct answers on the test, as shown in Figure 1.
TABLE 5: Correlations between performance on RTT and cognitive test performance.

\begin{tabular}{lcc}
\hline & \multicolumn{2}{c}{ Performance on RTT } \\
& Total correct answers & Total execution time \\
\hline MMSE & $r=0.344(p=0.003)^{*}$ & $r=-0.102(p=0.392)$ \\
SVF & $r=0.157(p=0.186)$ & $r=-0.114(p=0.336)$ \\
DS-DO & $r=0.308(p=0.008)^{*}$ & $r=-0.089(p=0.456)$ \\
DS-RO & $r=0.400(p=0.005)^{*}$ & $r=-0.022(p=0.853)$ \\
\hline
\end{tabular}

MMSE $=$ Mini-Mental State Examination; SVF = semantic verbal fluency; $\mathrm{DS}-\mathrm{DO}=$ digit span in direct order; DS-RO = digit span in reverse order.

${ }^{*}$ Statistically significant difference.

3.3. Correlations between Performance on RTT and Cognitive Tests. Although the three groups exhibited no differences in education, in MMSE, or on the communication functionality questionnaire, some variables were correlated with group performance as a whole on the RTT, as shown in Table 5. There was a significant correlation between total number of correct answers on the RTT and MMSE score, digit span in direct and reverse order, and education (positive correlations).

\section{Discussion}

The results of this study show an age effect on auditory sentence comprehension, only for more complex commands. For number of correct answers, the groups exhibited similar performance, differing only on the last two subtests (adults performed better than the young-old and the old-old). However, the measurement of execution time differentiated the groups with respect to subtest 2 . In general, the time required to complete the task increased with age. Additionally, there 
was a correlation between the number of total correct answers on the RTT, education, and performance on the cognitive tests: MMSE (global cognitive measures), direct digit span (attention), and reverse digit span (working memory).

The differentiation of the groups based on the number of correct answers on subtests 9 and 10 shows the increased burden of working memory in these blocks, such as increasing linguistic (syntactic) complexity by introducing a variety of grammatical constructions into statements. The results showed a reduction in performance (lower scores and longer execution time) proportional to the increase in the extent and syntactic complexity of the stimulus.

One of the most important abilities required to understand longer utterances is working memory, which stores verbal information, allows for comprehension of speech sequences, and organizes responses [8, 9]. According to McNeil and Prescott [22], the RTT provides a direct measure of short-term memory, especially the phonological loop of working memory, comprehension of various types of sentences and their transformations, and understanding of specific vocabulary and certain semantic relations (conditional phrases).

According to the language model proposed by Shalom and Poeppel [44], language processing can be divided into three main processes: analysis, storage, and synthesis, which require the involvement of large brain networks. All three processes appear to be linked to performance on the RTT because the test commands must be analyzed, interpreted based on phonological, syntactic, and semantic processes, and summarized using motor output (which requires visuospatial analysis, planning, coordination, and working memory), perhaps explaining the correlations with cognitive test performance.

A number of studies have consistently shown a decline in working memory with age and how this skill can interfere with the performance of language comprehension tasks [9, $45,46]$. Aging may affect the ability to process large amounts of information, a difficulty that may require additional strategies when applying concurrent tasks, such as listening and manipulating elements [47].

One explanation for the equivalence of the performance of older adults is that they have realized compensation because the working memory (also evaluated in the RTT) is extremely vulnerable to aging. In our study, even the old-old adults showed scores similar to those of adults.

A feature of the RTT is that it allows information to be grouped into meaning units (chunks) for retention and command execution. According to Gilchrist et al. [10], in retention tasks, words tend to be grouped; they are not processed separately, and the same applies to the retaining command of the propositions. In the case of the TT, commands gather propositions whose words are composed in an unpredictable way and therefore do not allow for clustering; there is no syntactic or semantic plausibility. Thus, the words are processed as separate items, which burdens the working memory.

Results reported in the literature regarding the effects of aging on the accuracy of responses on the TT are conflicting. Wertz et al. [21] applied only part 5 of the TT and found a correlation with age and a gradual decline in performance after age of 40. Emery [27] observed a decline in individuals aged 30-93 years, with lower scores in the elderly (7593 years). By contrast, Peña-Casanova et al. [28] evaluated subjects between 50 and 94 years of age and found little effect of age on TT performance. Snitz et al. [29] assessed elderly over 65 years and showed that performance on the Indiana University version of the TT was associated with younger age. Yang et al. [30] showed that seniors aged 65 years and older performed worse on the TT than did other groups.

The conflicting data can be explained by the different scoring systems used and different age groups studied. With respect to an analysis of execution time on the RTT, the elderly required more time to process information and compensate for possible auditory processing difficulties but exhibited similar results to adults regarding the number of correct answers for the majority of the test.

In this respect, Kim et al. [31] argued that the binary scoring system of hit-error (accuracy) used in scoring the TT is not sensitive enough to detect the effect of aging and established a performance measurement based on response time rather than accuracy. The authors found significant correlations with age above 65 years and noted that time measures can be more sensitive for measuring differences in verbal comprehension in this population.

The facilitation of auditory comprehension, particularly when there is more time to engage the compensation mechanism for signal processing deficit to perform tasks related to this language skill, corroborates data reported in the literature [16].

Similar compensations were observed in studies involving functional magnetic resonance imaging, where performance in sentence comprehension was associated with brain activity in certain areas. Older people, who exhibited similar performance to young people, showed additional activity in those areas where activity is typically found in young people. The elderly activated areas of the right hemisphere related to articulatory recapitulation of the phonological loop [15]. The present study provides evidence for this same phenomenon in the elderly subjects assessed. Therefore, it should be recognized that some aspects of the functioning of working memory resist aging-related loss, such as those related to vocal and subvocal rehearsal, and can support compensation for sentence comprehension.

Similarly, our results show that measures of time, especially execution time, are more sensitive for consistently detecting the effects of aging, regardless of hit analysis (binary or multidimensional), and the differences are evident even in young elderly (from 60 years). The fact that elderly required more time to complete the task but showed similar performance to younger individuals in subtests 1 to 8 of the RTT, which contained commands with simple or coordinated propositions, suggests the integrity of less complex syntactic processes [22].

Aging compensation mechanisms are related to cognitive reserve. Cognitive reserve theory recognizes that factors such as education, parental education, occupation, and reading habits may help maintain the performance of the elderly, particularly, naming, grammar comprehension, 
and vocabulary tasks [11]. Among these factors, education is highlighted because it is closely related to working memory skills [48] and recruited in the comprehension of syntactically complex sentences. [11]. It is possible that the education factor has provided the elderly maintenance skills necessary for the performance of the RTT, although they needed an increased runtime strategy.

The RTT has been an interesting tool to study the effect of aging on the auditory sentence comprehension. The addition of temporal measures and the correlation with other cognitive tests can refine the reasoning about the underlying processes of syntactic comprehension. This perspective indicates the need for additional studies.

Moreover, the analysis of execution time helps inform the possibilities for cognitive stimulation in the elderly, such as the development of programs related to processing in temporal aspects of working memory.

The main limitation of this study was the absence of reaction time analysis, computerized records, or even videos that allow for qualitative and quantitative refinement of observations such as the nature of test errors. Another important limitation was the absence of functional imaging studies to confirm and describe the nature of the compensation processes.

This study raises the prospect of further investigations, such as studies on the relationship between performance on the RTT and other language parameters, for example, naming, repetition, and written language.

\section{Conclusions}

Young-old and old-old subjects showed similar performance to adults in auditory comprehension task as measured by the number of correct answers on RTT, while differing from adults on the last two subtests. However, elderly required more time to respond to commands. This behavior shows that the execution time measurement is sensitive for detecting the effects of age. Sentence comprehension ability was correlated with performance on cognitive tests, particularly, attention and working memory. Healthy aging is characterized by the ability to compensate for difficulties in linguistic processing, which allows the elderly to maintain normal function in everyday life situations.

\section{Conflict of Interests}

The authors declare no conflict of interests regarding the publication of this paper.

\section{Authors' Contribution}

The authors contributed equally to this paper.

\section{Acknowledgment}

This study was supported by the Conselho Nacional de Desenvolvimento Científico e Tecnológico (CNPq).

\section{References}

[1] E. Dirkx and J. Richard, "Cognition et vieillissement," in Psychogerontologie, J. Richard and E. Dirkx, Eds., Masson, Paris, France, 1996.

[2] B. Ska and Y. Joanette, "Vieillissement normal et cognition," Medecine/Sciences, vol. 22, pp. 284-287, 2006.

[3] S. Kemper, "Language and aging," in The Handbook of Aging and Cognition, F. I. M. Craik and T. A. Salthouse, Eds., pp. 213-270, Lawrence Erlbaum Associates, Hillsdale, NJ, USA, 1992.

[4] B. B. Shadden, "Language and communication changes with aging," in Aging and Communication: for Clinicians by Clinicians, B. B. Shadden and M. A. Toner, Eds., pp. 135-170, PROEd, Austin, Tex, USA, 1997.

[5] B. A. Schneider, M. Daneman, and M. K. Pichora-Fuller, "Listening in aging adults: from discourse comprehension to psychoacoustics," Canadian Journal of Experimental Psychology, vol. 56, no. 3, pp. 139-152, 2002.

[6] M. K. Pichora-Fuller, "Cognitive aging and auditory information processing," International Journal of Audiology, vol. 42, no. 2, pp. S26-S32, 2003.

[7] J. B. Orange, "Language and communication disorders in older adults: selected considerations for clinical audiology," in Hearing Care for Adults, pp. 87-102, 2009.

[8] A. Baddeley, "Working memory and language: an overview," Journal of Communication Disorders, vol. 36, no. 3, pp. 189-208, 2003.

[9] G. Waters and D. Caplan, "The relationship between age, processing speed, working memory capacity, and language comprehension," Memory, vol. 13, no. 3-4, pp. 403-413, 2005.

[10] A. L. Gilchrist, N. Cowan, and M. Naveh-Benjamin, "Working memory capacity for spoken sentences decreases with adult ageing: recall of fewer but not smaller chunks in older adults," Memory, vol. 16, no. 7, pp. 773-787, 2008.

[11] R. López-Higes, S. Rubio-Valdehita, J. M. Prados, and M. Galindo, "Cognitive reserve and linguistic skills in healthy elderly persons," Revista de Neurologia, vol. 57, no. 3, pp. 97-102, 2013.

[12] Y. Stern, C. Habeck, J. Moeller et al., "Brain networks associated with cognitive reserve in healthy young and old adults," Cerebral Cortex, vol. 15, no. 4, pp. 394-402, 2005.

[13] M. Lövdén, L. Bäckman, U. Lindenberger, S. Schaefer, and F. Schmiedek, "A theoretical framework for the study of adult cognitive plasticity," Psychological Bulletin, vol. 136, no. 4, pp. 659-676, 2010.

[14] F. Dolcos, H. J. Rice, and R. Cabeza, "Hemispheric asymmetry and aging: right hemisphere decline or asymmetry reduction," Neuroscience and Biobehavioral Reviews, vol. 26, no. 7, pp. 819825, 2002.

[15] A. Wingfield and M. Grossman, "Language and the aging brain: patterns of neural compensation revealed by functional brain imaging," Journal of Neurophysiology, vol. 96, no. 6, pp. 28302839, 2006

[16] D. C. Park and I. M. McDonough, "The dynamic aging mind: revelations from functional neuroimaging research," Perspectives on Psychological Science, vol. 8, no. 1, pp. 62-67, 2013.

[17] E. De Renzi and L. A. Vignolo, “The Token Test: a sensitive test to detect receptive disturbances in aphasics," Brain, vol. 85, no. 4, pp. 665-678, 1962.

[18] F. J. Spellacy and O. Spreen, "A short form of the token test," Cortex, vol. 5, no. 4, pp. 390-397, 1969. 
[19] F. Van Harskamp and H. R. Van Dongen, "Construction and validation of different short forms of the token test," Neuropsychologia, vol. 15, no. 3, pp. 467-470, 1977.

[20] E. De Renzi and P. Faglioni, "Development of a shortened version of the Token test," Cortex, vol. 14, no. 1, pp. 41-49, 1978.

[21] R. T. Wertz, R. L. Keith, and D. D. Custer, "Normal and aphasic behavior on measure of auditory input and a measure of verbal output," in Proceedings of the American Speech Language Hearing Association Annual Convention, Chicago, Ill, USA, 1971.

[22] M. R. McNeil and T. E. Prescott, Revised Token Test, Pro-Ed, Austin, Tex, USA, 1978.

[23] L. L. Mansur, M. Radanovic, D. Rüegg, L. I. Z. De Mendonça, and M. Scaff, "Descriptive study of 192 adults with speech and language disturbances," Sao Paulo Medical Journal, vol. 120, no. 6, pp. 170-174, 2002.

[24] S. N. Jones and C. R. Ayers, "Psychometric properties and factor structure of an expanded CERAD neuropsychological battery in an elderly VA sample," Archives of Clinical Neuropsychology, vol. 21, no. 4, pp. 359-365, 2006.

[25] J. J. de Paula, L. Bertola, R. Nicolato, E. N. de Moraes, and L. F. Malloy-Diniz, "Evaluating Language Comprehension in Alzheimer's disease: the use of the Token Test," Arquivos de Neuro-Psiquiatria, vol. 70, no. 6, pp. 435-440, 2012.

[26] L. Frings, K. Dressel, S. Abel et al., "Longitudinal cerebral diffusion changes reflect progressive decline of language and cognition," Psychiatry Research: Neuroimaging, vol. 214, no. 3, pp. 395-401, 2013.

[27] O. B. Emery, "Linguistic decrement in normal aging," Language and Communication, vol. 6, no. 1-2, pp. 47-64, 1986.

[28] J. Peña-Casanova, S. Quiñones-Úbeda, N. Gramunt-Fombuena et al., "Spanish multicenter normative studies (NEURONORMA project): Norms for boston naming test and token test," Archives of Clinical Neuropsychology, vol. 24, no. 4, pp. 343-354, 2009.

[29] B. E. Snitz, F. W. Unverzagt, C.-C. H. Chang et al., "Effects of age, gender, education and race on two tests of language ability in community-based older adults," International Psychogeriatrics, vol. 21, no. 6, pp. 1051-1062, 2009.

[30] L. Yang, F. W. Unverzagt, Y. Jin et al., "Normative data for neuropsychological tests in a rural elderly Chinese cohort," The Clinical Neuropsychologist, vol. 26, no. 4, pp. 641-653, 2012.

[31] H. H. Kim, J. E. Sung, J. W. Kim et al., "Response time measurements in the iOS app-based Token Test, the Brief Token Test in the elderly," Geriatrics and Gerontology International, vol. 14, no. 4, pp. 969-974, 2014.

[32] M. F. Folstein, S. E. Folstein, and P. R. McHugh, "Mini-mental state: a practical method for grading the cognitive state of patients for the clinician," Journal of Psychiatric Research, vol. 12, no. 3, pp. 189-198, 1975.

[33] S. M. D. Brucki, R. Nitrini, P. Caramelli, P. H. F. Bertolucci, and I. H. Okamoto, "Sugestões para o uso do mini-exame do estado mental no Brasil," Arquivos de Neuro-Psiquiatria, vol. 61, no. 3, pp. 777-781, 2003.

[34] S. M. D. Brucki, S. M. F. Malheiros, I. H. Okamoto, and P. H. F. Bertolucci, "Dados normativos para o teste de fluência verbal categoria animais em nosso meio. [Normative data: category verbal fluency]," Arquivos de Neuro-Psiquiatria, vol. 55, no. 1, pp. 56-61, 1997 (Portuguese).

[35] D. A. Wechsler, Wechsler Memory Scale-Revised Manual, Psychological Corporation, New York, NY, USA, 1987.

[36] G. E. Smith and R. J. Ivnik, "Normative neuropsychology," in Mild Cognitive Impairment, R. C. Petersen, Ed., pp. 63-68, Oxford University Press, New York, NY, USA, 2003.
[37] A. E. Damin, Questionnaire of cognitive change as a method for dementia screening [Teses de doutorado], Universidad de São Paulo, São Paulo, Brazil, 2011 (Portuguese).

[38] J. I. Sheikh and J. A. Yesavage, "Geriatric Depression Scale (GDS). Recent evidence and development of a shorter version," in Clinical Gerontology: A Guide to Assessment and Intervention, T. L. Brink, Ed., pp. 165-173, The Haworth Press, New York, NY, USA, 1986.

[39] O. P. Almeida and A. S. Almeida, "Reliability of the Brazilian version of the abbreviated form of Geriatric Depression Scale (GDS) short form," Arquivos de Neuro-Psiquiatria, vol. 57, no. 2, pp. 421-426, 1999.

[40] C. Fratalli, C. Thompson, A. Holland, C. Wohl, and M. Ferketic, Functional Assessment of Communication Skills for Adults (ASHA FACS), American Speech-Language-Hearing Association, Rockville, Md, USA, 1995.

[41] I. A. M. De Carvalho and L. L. Mansur, "Validation of ASHA FACS-functional assessment of communication skills for Alzheimer disease population," Alzheimer Disease and Associated Disorders, vol. 22, no. 4, pp. 375-381, 2008.

[42] V. D. O. Martins and C. R. F. de Andrade, "Speech fluency developmental profile in brazilian Portuguese speakers," PróFono Revista de Atualização Científica, vol. 20, no. 1, pp. 7-12, 2008.

[43] M. Ayres, M. Ayres Junior, D. L. Ayres, and A. S. Santos, BioEstat 5.0-Statistical Applications in the Areas of Biomedical Sciences, ONG Mamiraua, Belém, Brazil, 2007.

[44] D. B. Shalom and D. Poeppel, "Functional anatomic models of language: assembling the pieces," Neuroscientist, vol. 14, no. 1, pp. 119-127, 2008.

[45] S. Ramón López-Higes, M. Susana Rubio Valdehita, T. M. Aragoneses, and D. Del Río, "Interindividual variability in vocabulary, sentence comprehension and working memory in the elderly: effects of cognitive deterioration," Spanish Journal of Psychology, vol. 13, no. 1, pp. 75-87, 2010.

[46] A. B. Hancock, L. L. LaPointe, J. A. G. Stierwalt, M. S. Bourgeois, and R. A. Zwaan, "Computerized measures of verbal working memory: performance in healthy elderly participants," Contemporary Issues in Communication Science and Disorders, vol. 34, pp. 73-85, 2007.

[47] S. Kemper, R. E. Herman, and J. Nartowicz, "Different effects of dual task demands on the speech of young and older adults," Aging, Neuropsychology, and Cognition, vol. 12, no. 4, pp. 340358, 2005.

[48] A. L. Jefferson, L. E. Gibbons, D. M. Rentz et al., "A life course model of cognitive activities, socioeconomic status, education, reading ability, and cognition," Journal of the American Geriatrics Society, vol. 59, no. 8, pp. 1403-1411, 2011. 


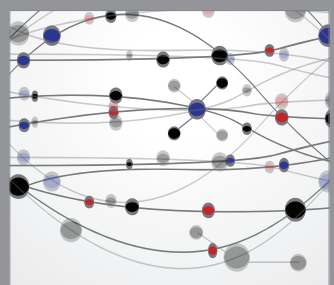

The Scientific World Journal
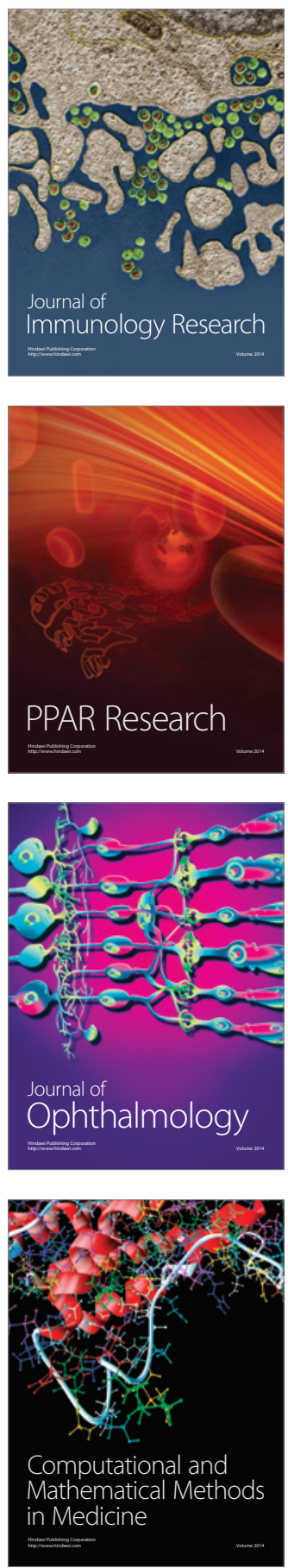

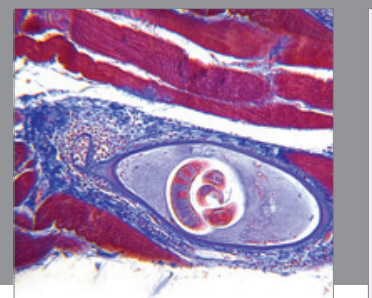

Gastroenterology

Research and Practice
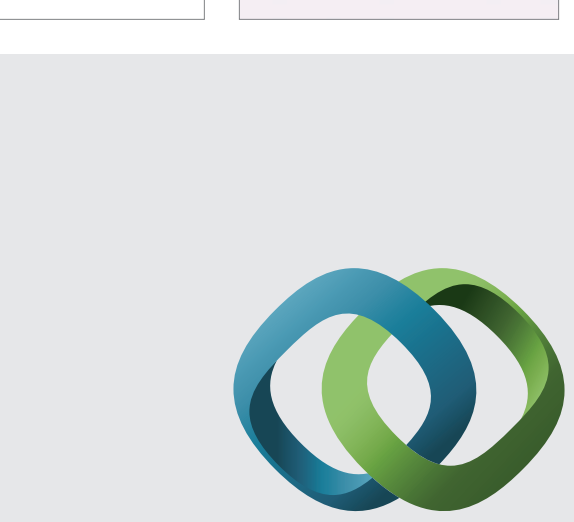

\section{Hindawi}

Submit your manuscripts at

http://www.hindawi.com
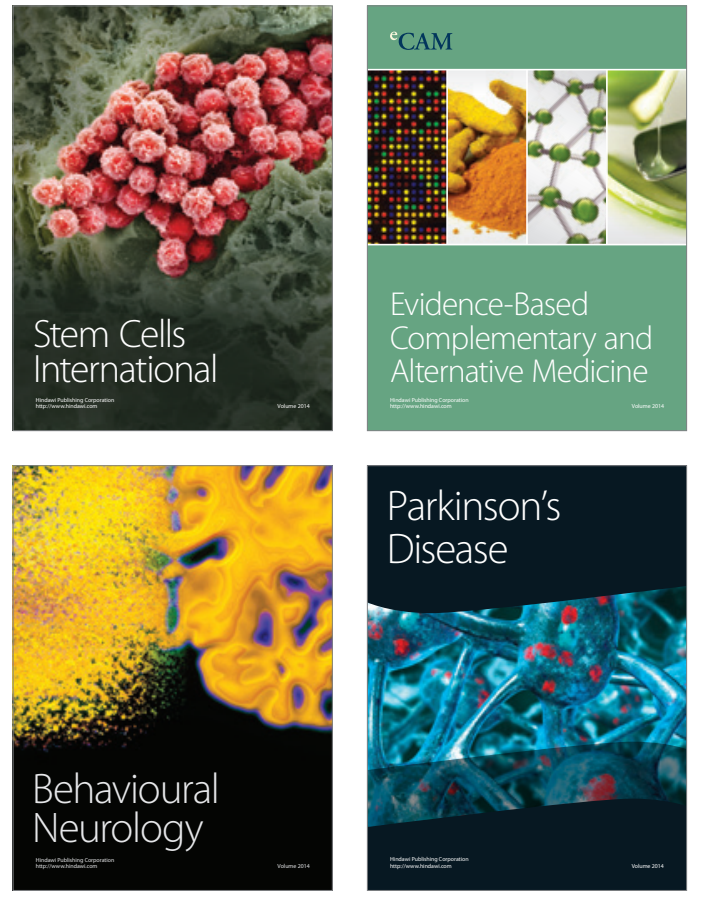
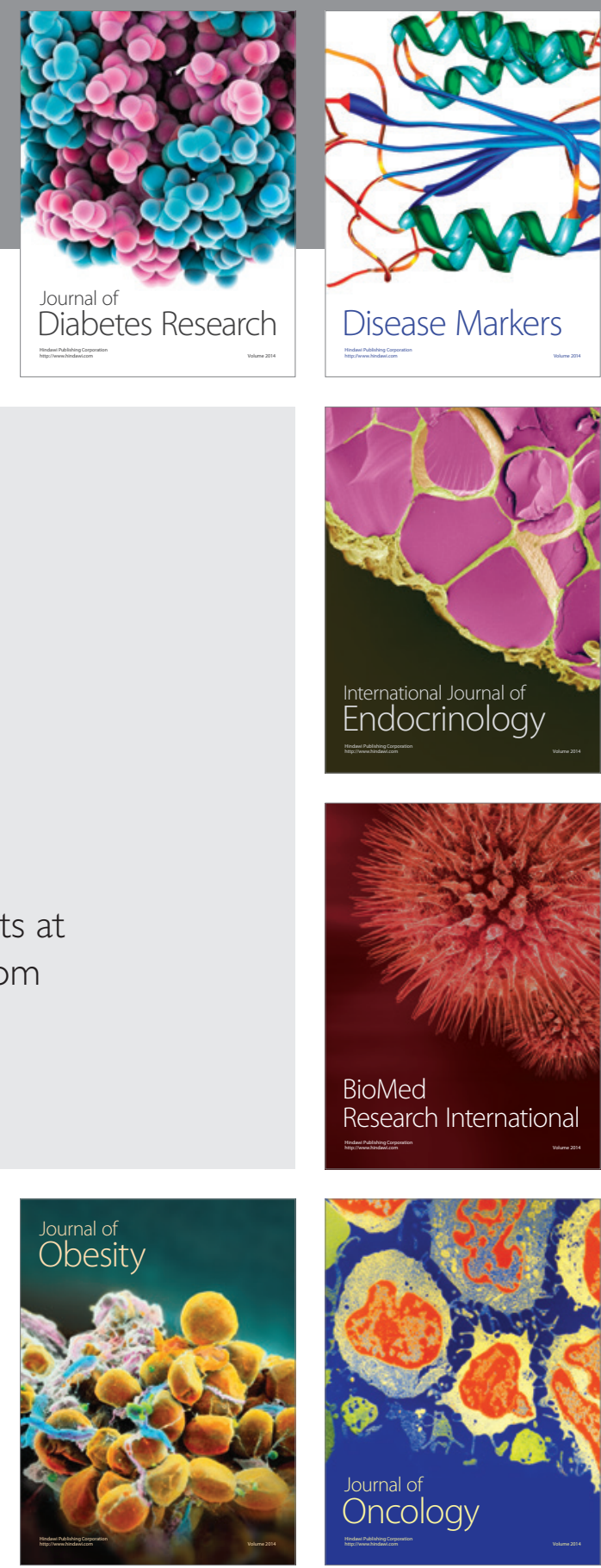

Disease Markers
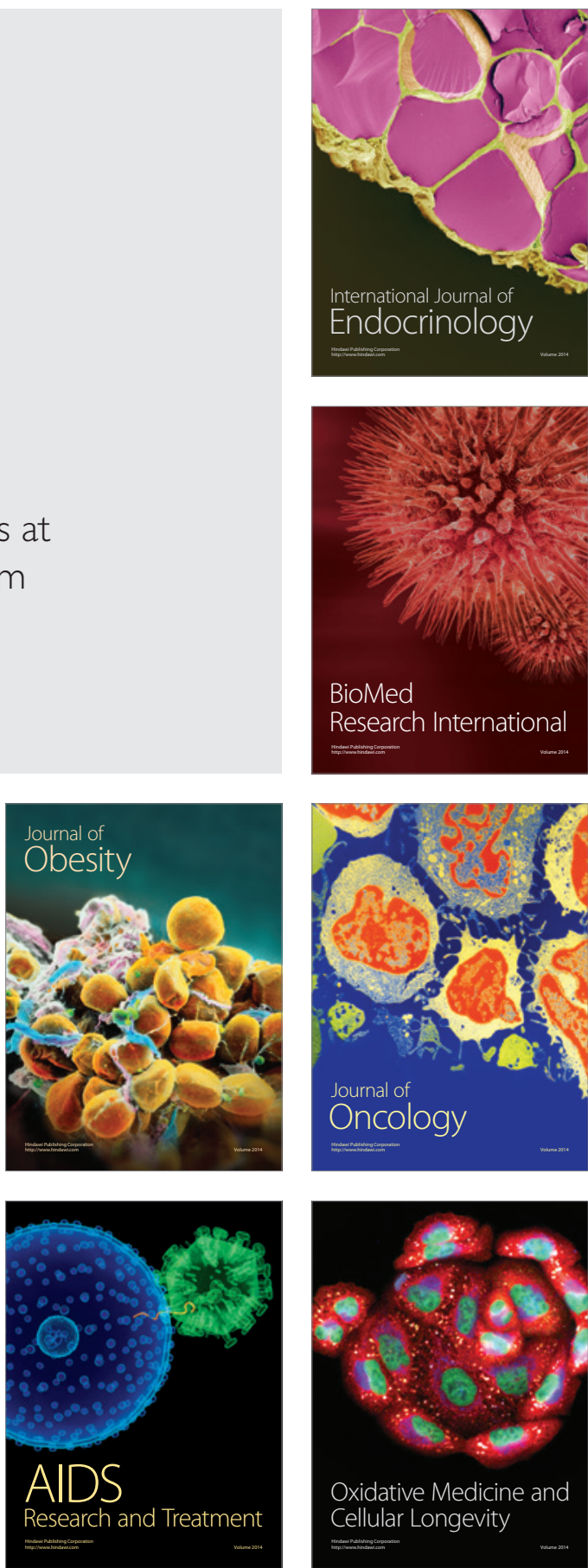